\title{
Influence of Pilot Gas Composition on Convective Pattern of Weld Pool Surface in Plasma Keyhole Arc Welding
}

\author{
by Nguyen Van Anh*, Shinichi Tashiro*, Bui Van Hanh ${ }^{* *}$ and Manabu Tanaka*
}

\begin{abstract}
This investigation is purposed to clarify the influence of pilot gas composition to convective pattern on the weld pool surface in Plasma keyhole arc welding process. In order to clarify this, the convective pattern on the top surface of weld pool was investigated in both cases of pilot gas: pure Ar and Ar mixture with 10\% hydrogen. For estimating the convective pattern, the zirconia particles with diameter of $0.03 \mathrm{~mm}$ were utilized as tracers. After welding, using the software (Dipp-motion, Detect Co., Ltd) for analyzing the movement of zirconia particles, the convective pattern was estimated. In case of pure Ar, zirconia particles were in circulated motions just behind keyhole on the top surface of weld pool, and transported to rear part of weld pool on the bottom surface. In case of Ar mixture with $10 \%$ hydrogen, zirconia particles on both surfaces (top surface and bottom surface) of weld pool were in circulated motions behind keyhole. Furthermore, the weld bead shape was narrow on both top surface and bottom surface in case of pure Ar. Meanwhile, the weld bead shape was wide on both top surface and bottom surface in case of Ar mixture with $10 \%$ hydrogen.
\end{abstract}

Key Words: Plasma keyhole arc welding, Convective pattern, Zirconia particle, Pilot gas, Weld pool

\section{Introduction}

Plasma Arc Welding (PAW) is a fusion arc welding process with higher penetration and lower distortion than conventional Gas Tungsten Arc Welding (GTAW). In comparison with Laser Beam Welding (LBW) and Electron Beam Welding (EBW) processes, PAW is more cost effective and more tolerant of joint separation, even though its energy is less dense. Consequently, it has found wide applications in industry such as: aerospace, shipbuilding, structure steel, etc ${ }^{1)}$. As with LBW and EBW, PAW can be operated in Plasma Keyhole Arc Welding (PKAW) mode.

In PKAW, the molten flow by arc near the keyhole is transported backward through both sides of the keyhole and therefore produces a weld pool. It is required to fill the void behind the keyhole with the molten flow for maintaining welding stability. There are two necessary conditions for welding stability: the molten flow on both sides must bridge the gap formed at the rear part by the passage of keyhole and, in addition, the molten flow is supported by the surface tension acting on the back surface of molten pool. To improve this welding stability, it is essential to study the keyhole formation mechanism by considering the behavior of the convection flow in weld pool. In order to understand and improve the behavior of the convection flow, it is necessary to research mechanisms involving transportation of the convection flow in weld pool in further details. The behavior described above is a result of a balance of forces acting on the surface and inside PKAW weld pool. As indicated in a previous paper, there were four principal forces driving the welding convection flow of welding arc processes: (i) drag force (shear force) on the liquid surface is produced by plasma flow through keyhole and plasma flow on the weld pool

${ }_{* *}^{*}$ Joining and Welding Research Institute, Osaka University ${ }^{* *}$ Hanoi University of Science and Technology, Hanoi, Viet Nam surface; (ii) buoyancy force is created due to the temperature difference within the weld pool; (iii) Lorentz force is generated due to the self-magnetic field of arc current within the weld pool and (iv) Marangoni force is caused by the temperature gradient on the surface of weld pool ${ }^{2}$. These forces, which depend mainly on the welding conditions used such as: welding current, welding voltage, shielding gas, welding speed, base metal, etc.

Recently, in order to obtain good welding quality, PKAW was investigated. However, these researches focused mainly on controlling the keyhole and the weld pool surface or controlling the welding robot.

For the purpose of improving the quality of welds, Zhang et al. ${ }^{3,4,5)}$ have attempted to observe the influence of welding speed and welding current to the change of the keyhole diameter and the weld pool surface using an Insulated Gate Bipolar Transistor (IGBT) power module. By using this module, welding current was controlled in pulse form to decrease the brightness of main arc. During the time of weak brightness of main arc, the keyhole and the weld pool surface were clearly visualized by High-Speed Video Camera (HSVC).

In order to achieve sound weld bead, Yamane et al. ${ }^{6,7,8)}$ investigated mainly developing algorithms for controlling feedback of welding robot through processing the weld pool images to track the weld-line based on the boundary between base metal and weld pool. During welding process, however, it was difficult to clearly distinguish the boundary due to too high brightness of main arc. To correctly control, the pulse current wave form was used to cut off main arc for a very short time.

$\mathrm{Wu}$ et al. ${ }^{9)}$ tried to achieve good quality of weld joints through controlling the keyhole stability. In order to do that, a welding current control unit for PKAW process was developed. During welding process, images of the keyhole and the weld pool surface were captured, as well as measuring the temperature from 
the bottom side of base metal. The main results showed the relationship of welding current and keyhole geometry parameters.

The weld pool formation mechanism depends mainly on various driving forces of the weld pool convection. However, the behaviors of the convective flow in weld pool and the keyhole formation mechanism have been not fully understood. Furthermore, in order to obtain deeper penetration of thickness welding plates, the mixture with hydrogen in pure Ar can be used to instead of pure Ar as pilot gas ${ }^{2}$. Since hydrogen is added in pilot gas, the convective pattern of weld pool can be changed. Therefore, this study focused on discussing the influence of chemical composition of pilot gas on the change of liquid flow of weld pool. To obtain this purpose, zirconia particles were utilized to observe the behavior of convective pattern on the weld pool surface with a HSVC.

\section{Experimental method}

A configuration diagram for observing the top surface and the bottom surface of weld pool is shown in Fig. 1. This visualization system consists of a transfer-type plasma arc welding torch (100WH, Nippon Steel Welding \& Engineering Co., Ltd.), a welding power (NW-300ASR, Nippon Steel Welding \& Engineering Co., Ltd.), base metal, shielding gas, pilot gas, a HSVC (Memrecam Q1v-V-209-M8, Nac Co., Ltd), a actuator (THK E56-06-0300H-TS, THK Co., Ltd), and a band-pass filter. The base metal of stainless steel sheet with dimensions of $300 \mathrm{x}$ $100 \times 4 \mathrm{~mm}$ was used. Its chemical composition is shown in Table 1. The pilot gas was pure $\mathrm{Ar}$ or Ar mixture with $10 \%$ hydrogen. Pure Ar was employed as the shielding gas. For protecting the backside of welding joints, a back shielding gas box (BSGB) was put on the welding jig. The shielding gas flow was introduced into the BSGB in order to prevent the negative influence of air to welding quality through two small holes. The back shielding gas flow rate was set at $10 \mathrm{~L} / \mathrm{min}$. The HSVC connecting with a computer had captured videos at $3000 \mathrm{fps}$ in each experiment in order to acquire clear images. An actuator controlled the welding speed of $3 \mathrm{~mm} / \mathrm{s}$. A band-pass filter with the wavelength of $550 \mathrm{~nm}$ was attached in front of HSVC. By using this band-pass filter, the relative brightness radiation of the arc was significantly decreased. Therefore, the movement of zirconia particles was clearly visualized. In addition, the magnification of weld pool images was controlled by a lens (Micro-Nikkon $105.0 \mathrm{~mm} \mathrm{f/2.8,} \mathrm{Nikkon} \mathrm{Co.,} \mathrm{Ltd).} \mathrm{Other} \mathrm{welding}$ conditions are shown in Table 2.

Table 1 Chemical composition of base metal.

\begin{tabular}{llllll}
\hline Elements & $\mathrm{C}$ & $\mathrm{Si}$ & $\mathrm{Mn}$ & $\mathrm{Ni}$ & $\mathrm{Cr}$ \\
Wt.\% & 0.06 & 0.44 & 0.96 & 8.19 & 18.22 \\
\hline
\end{tabular}

Table 2 Welding conditions.

\begin{tabular}{ll}
\hline Welding current & DC 120 A \\
Plasma gas & Pure Ar and Ar mixture with \\
& $10 \%$ hydrogen \\
Shielding gas & Pure Ar \\
Back shielding gas & Pure Ar \\
Arc length & $5 \mathrm{~mm}$ \\
Plasma gas flow rate & $1.75 \mathrm{~L} / \mathrm{min}$ \\
Shielding gas flow rate & $7.50 \mathrm{~L} / \mathrm{min}$ \\
Back shielding gas flow rate & $10 \mathrm{~L} / \mathrm{min}$ \\
\hline
\end{tabular}

To investigate the convective pattern on weld pool surface, zirconia particles with diameter of $0.03 \mathrm{~mm}$ were used. In order to put zirconia particles in holes on base metal, in each of experiments, one hole was drilled with each of them having the depth of $2 \mathrm{~mm}$ and the diameter of $1 \mathrm{~mm}$ as presented in Fig. 2 . The depth of $2 \mathrm{~mm}$ was suitable for particles to be introduced to both the top and bottom surfaces. It was confirmed that the depth of $1 \mathrm{~mm}$ also led to similar flow velocity field on the top surface of the weld pool. Afterwards, holes were cleaned by the ethanol and acetone solutions. Subsequently, they were dried in the air. After drying, several zirconia particles were put in each hole. Finally, base metal was fixed and welded with welding conditions setup. After welding, a computer with software for analyzing liquid flow (Dipp-motion, Detect Co., Ltd) was used to calculate the convective pattern on the surface of weld pool.

\section{Results and discussion}

In this paper, the convective pattern on the surfaces of weld pool was estimated through the movement of zirconia particles. The convective pattern on the top surface in both cases: pure Ar

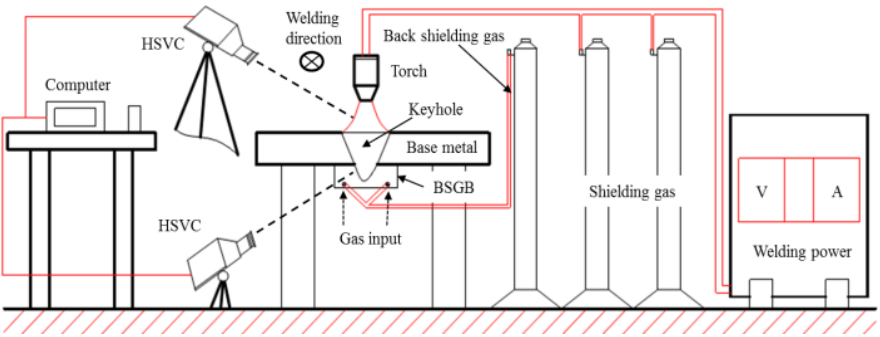

Fig. 1 A configuration diagram for observing weld pool.

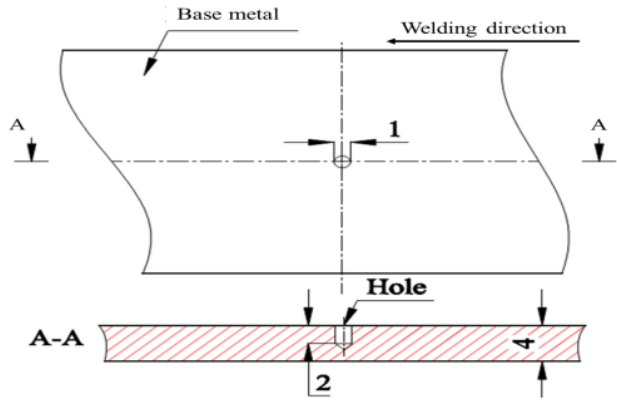

Fig. 2 Holes position on base metal. 
and $\mathrm{Ar}$ mixture with $10 \%$ hydrogen was presented in Fig. 3 (a) and (b). A schematic illustration of the convective pattern was shown in Fig. 3 (c). Most of zirconia particles were transported through both sides of keyhole. After accelerating in upward direction inside keyhole, and accelerating in backward direction on both sides of keyhole, zirconia particles were transported toward the center line of weld pool, and then was circulated behind keyhole. The circulated motion regions were located about $3.5 \mathrm{~mm}$ and $4.5 \mathrm{~mm}$ from keyhole in case of pure $\mathrm{Ar}$ and $\mathrm{Ar}$ mixture with $10 \%$ hydrogen, respectively. In both cases, the velocity was higher near the center line, and decreased to both sides of weld pool. In case of pure Ar, the maximum velocity was about $0.70 \mathrm{~m} / \mathrm{s}$ occurring near both sides of keyhole. The velocity of particles in circulated motion region was about $0.15 \mathrm{~m} / \mathrm{s}$. On the other hand, in case of Ar mixture with $10 \%$ hydrogen, the velocity of convective pattern was faster. The maximum velocity was about $1.00 \mathrm{~m} / \mathrm{s}$ occurring near both sides of keyhole. The velocity was decreased to $0.25 \mathrm{~m} / \mathrm{s}$ before entering into circulated motion region.

The convective pattern on the bottom surface of weld pool in both cases: pure $\mathrm{Ar}$ and $\mathrm{Ar}$ mixture with 10\% hydrogen was presented in Fig. 4 (a) and (b). A schematic illustration was shown in Fig. 4 (c). In case of pure Ar shown in Fig. 6 (a) and (c), most of zirconia particles appeared just behind keyhole. Zirconia particles around the center line of weld pool were more strongly accelerated than that near both sides of keyhole. As a result, the velocity of zirconia particles around the center line was higher compared to that near both sides of keyhole. In this case, after accelerating in downward direction inside keyhole, zirconia particles were transported with high velocity to the rear part of weld pool. The velocity of particles was gradually decreased from keyhole to the rear part of weld pool. The maximum velocity was about $1.40 \mathrm{~m} / \mathrm{s}$ for particles moving near the center line. It decreased to $0.40 \mathrm{~m} / \mathrm{s}$ near both sides of weld pool. For convective pattern near the rear part of weld pool, zirconia particles tended into circulated motions with the velocity of about $0.15 \mathrm{~m} / \mathrm{s}$.

Meanwhile, Fig. 4 (b) and (c) described the convective pattern on the bottom surface of weld pool in case of Ar mixture with $10 \%$ hydrogen (note that the magnification of (b) was changed from (a)). In this case, zirconia particles mostly came through both sides of keyhole. After accelerating in downward direction inside keyhole, and accelerating in backward direction near both sides of keyhole, zirconia particles moved toward the center area of weld pool just behind keyhole. The velocity of zirconia particles was much slower in comparison with that in case of pure Ar. The maximum velocity was about $0.60 \mathrm{~m} / \mathrm{s}$ occurring near the both sides of keyhole and just behind keyhole.

Fig. 5 indicated the shapes of weld bead on both surfaces and zirconia particle position in case of pure Ar. Weld beads on top surface and bottom surface were narrow. The bead width on top surface was about $6.0 \mathrm{~mm}$ and bottom surface was about $3.5 \mathrm{~mm}$. The keyhole diameter was about $5.0 \mathrm{~mm}$ on the top surface and was about $2.5 \mathrm{~mm}$ on the bottom surface. A-A1 line shows the position, in which the zirconia particles were put in.

Fig. 6 portrayed the shapes of weld bead and zirconia particle position in case of Ar mixture with 10\% hydrogen. Weld beads on top surface and bottom surface were wide. The bead width on top surface was about $7.5 \mathrm{~mm}$ and bottom surface was about $6.0 \mathrm{~mm}$. The keyhole diameter was about $7.0 \mathrm{~mm}$ on the top surface and was about $5.0 \mathrm{~mm}$ on the bottom surface. The keyhole diameter in this case was larger than that in case of pure Ar. These differences can be explained by increase in the energy density of the arc and plasma flow velocity. B-B1 line shows the position, in which the zirconia particles were put in.

Recently, Mastuda et al. ${ }^{10)}$ presented the velocity field on the weld pool surface in TIG welding. They measured that the maximum velocity was about $0.2 \mathrm{~m} / \mathrm{s}$ occurring just behind the arc. Another one, Wu et al. ${ }^{11)}$ measured that the average velocity was about $0.15 \mathrm{~m} / \mathrm{s}$ just in front of weld pool and $0.03 \mathrm{~m} / \mathrm{s}$ near the tail of weld pool in case of GMA welding. Weld pool formation mechanisms of TIG welding and GMA welding are different with PKAW. In these cases (TIG welding and GMA welding), shear force, electromagnetic force and Marangoni force are driving forces ${ }^{2}$. Nevertheless, shear force was not so strong due to the low plasma flow velocity. It can be considered that shear force was not main driving force in these cases.

On the other hand, in case of PKAW, it was expected that the plasma flow velocity was much higher than those of TIG welding and GMA welding. Furthermore, the plasma flowed nearly parallel to the weld pool surface inside the keyhole because the base metal was fully penetrated and the keyhole was completely opened. Therefore, the shear force was considered to be the main driving force especially on the bottom surface. As a result, the flow velocity on the weld pool surface was much higher in comparison with TIG welding and GMA welding.

Furthermore, in case of PKAW, the plasma gas flow along the weld pool surface was very strong. It can push zirconia directly particles toward the rear part of weld pool. However, in this study, it was seen that zirconia particles were circulated motion behind the keyhole. In addition, Fig. 7 shows time sequential figures on upward flow on the weld pool surface. The time for figure (a) was set to be 0 s. It was confirmed that the particle inside the keyhole moved upward which was in the opposite direction against the plasma gas flow. These results means that plasma gas flow hardly affect the particle motion at least in this experiment. 


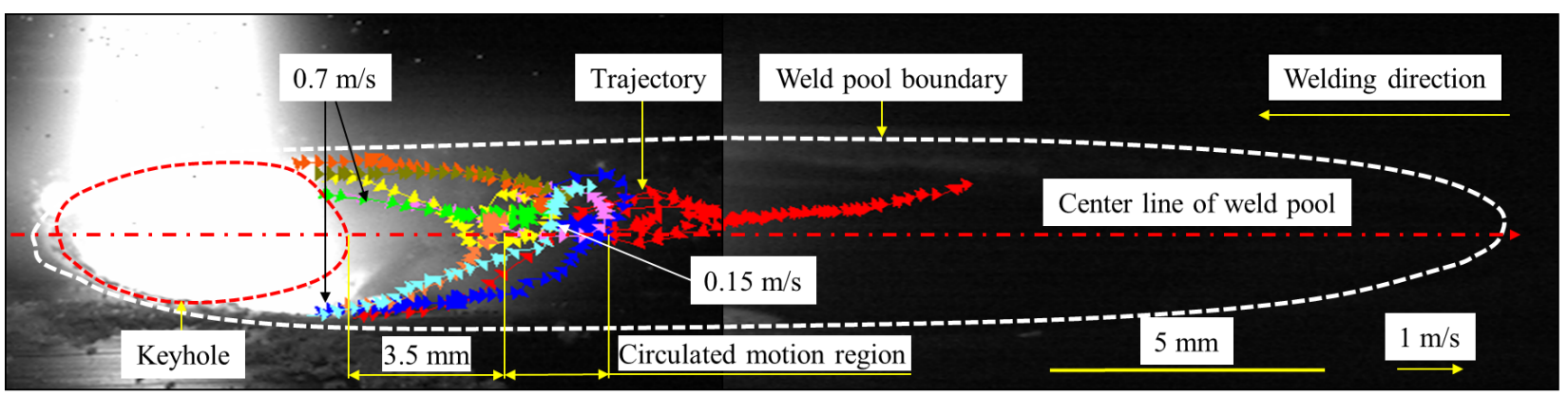

(a) Pure Ar

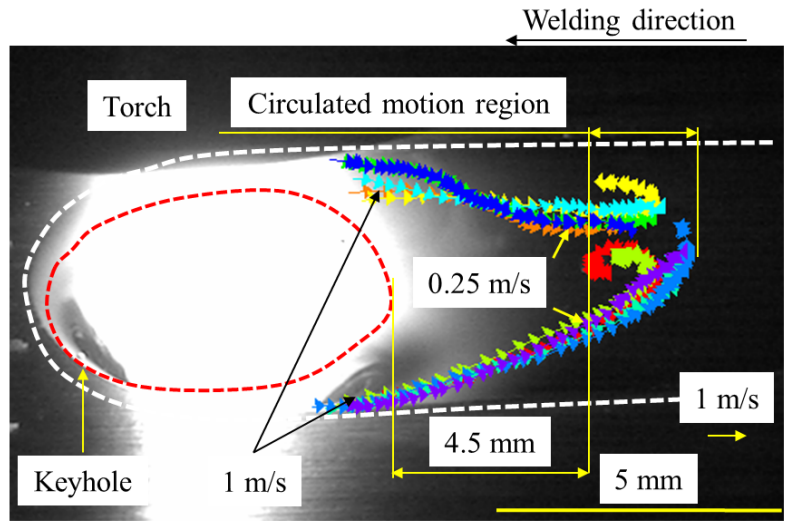

(b) Ar mixture $10 \%$ hydrogen

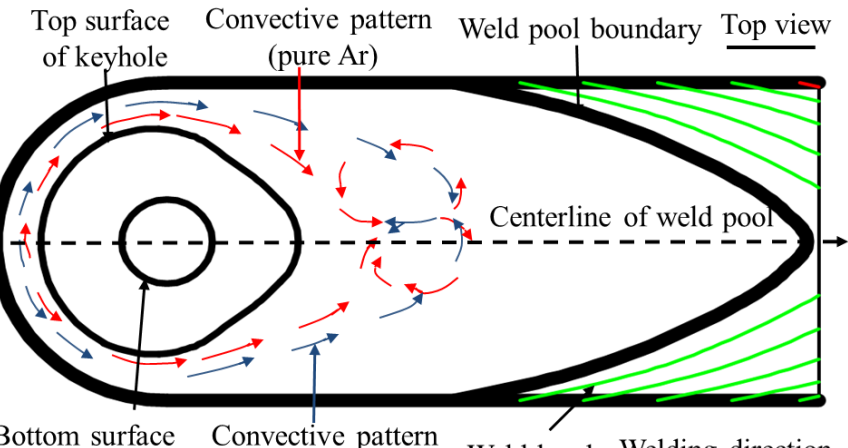
$\begin{array}{cl}\begin{array}{c}\text { Bottom surface } \\ \text { of keyhole }\end{array} & \begin{array}{c}\text { Convective pattern } \\ (\text { Ar mixture } 10 \% \mathrm{H})\end{array} \text { Weld bead }\end{array}$ Welding direction

(c) Schematic illustration

Fig. 3 Convective pattern on the top surface.

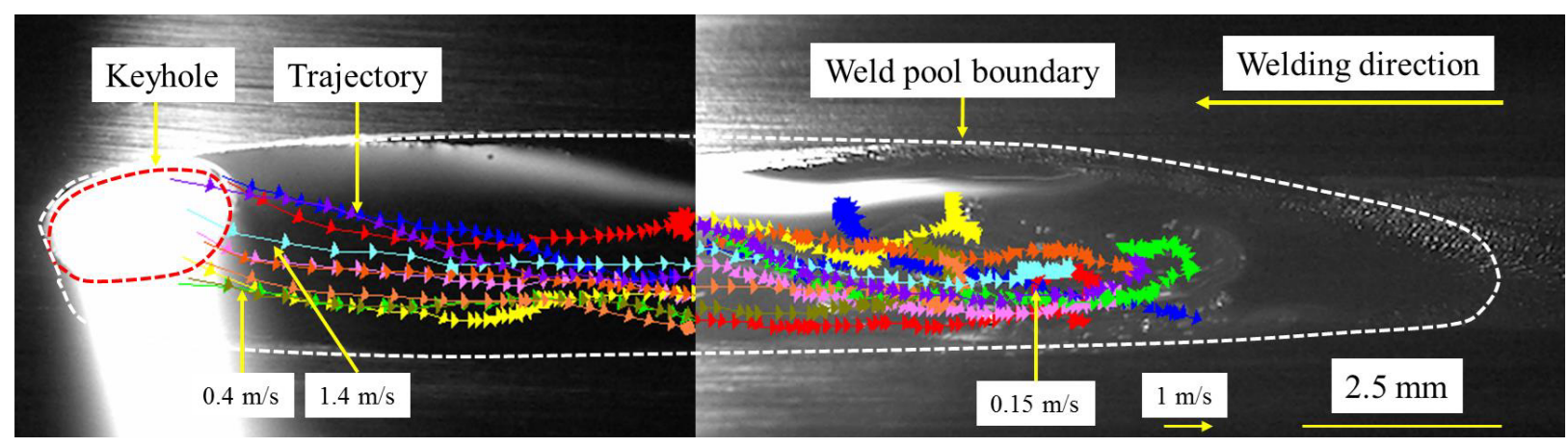

(a) Pure Ar

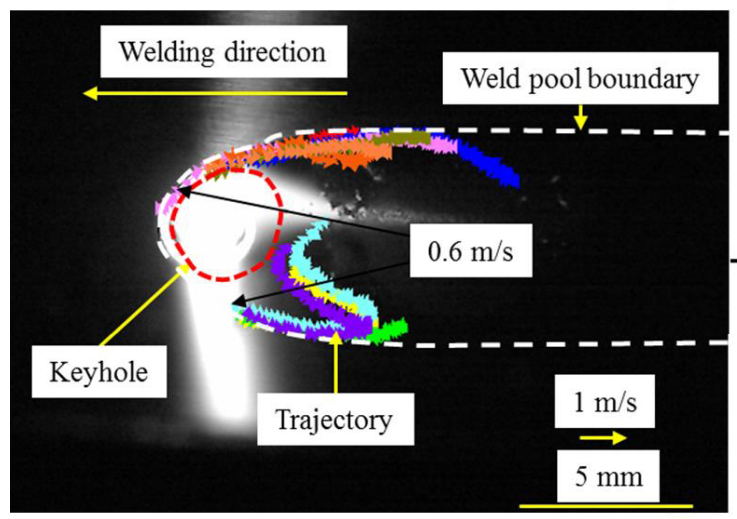

(b) Ar mixture $10 \%$ hydrogen

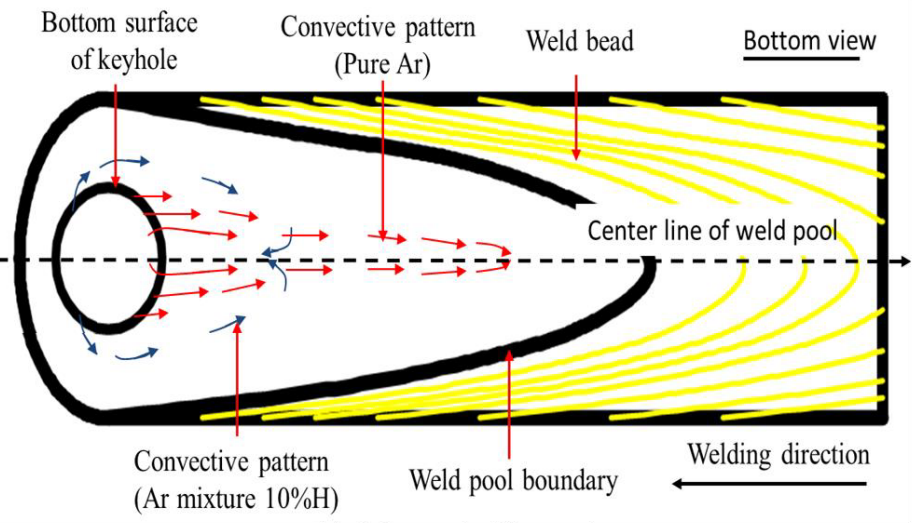

(c) Schematic illustration

Fig. 4 Convective pattern on the bottom surface. 


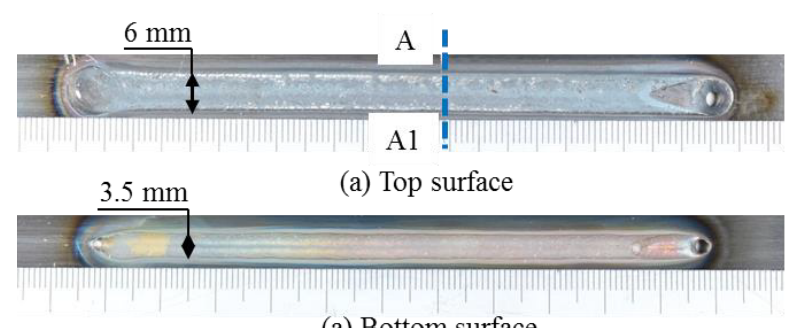

(a) Bottom surface

Fig. 5 Weld bead appearance in pure Ar case.

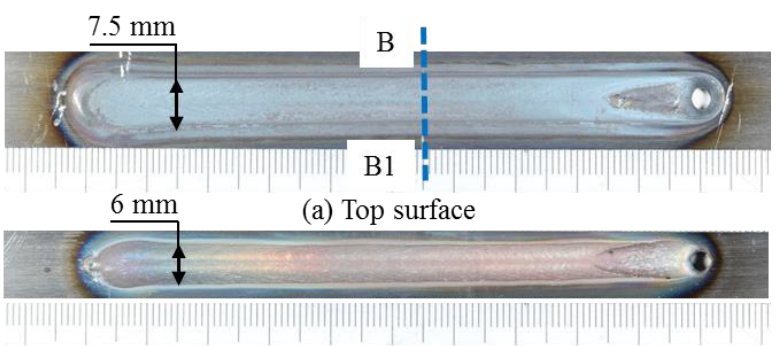

(b) Bottom surface

Fig. 6 Weld bead appearance in Ar mixture 10\% hydrogen.

In PKAW, shear force consists of two components. First component was caused by small amounts of gas flow blowing along the top surface. This component mainly affected to the convective pattern on the top surface. Another component was produced by most amounts of gas flow transporting through the keyhole from top surface to bottom surface. This component mainly affected to the convective pattern on the bottom surface. On the other hand, since small amounts of hydrogen (high specific heat) were added in the pilot gas, due to Thermal Pinch effect, the energy density of the arc was increased and the arc was constricted, hence the velocity of plasma flow was highly increased $^{2}$. Consequently, the velocity of the convective pattern on the top surface in case of Ar mixture with $10 \%$ hydrogen was higher than that in case of pure Ar. This also caused circulated motion region in case of Ar mixture with 10\% hydrogen more far from keyhole compared to pure Ar. The velocity of particles on the bottom surface was clearly slower in case of Ar mixture with $10 \%$ hydrogen. Hence, weld bead shapes on both surfaces (top surface and bottom surface) were wider those in case of mixture pilot gas, especially the weld bead on the bottom surface. It is considered that the decrease in velocity was caused by change in the convective pattern near the bottom surface. In order to clarify this phenomenon, observation of the convective pattern inside the weld pool by X-ray is also necessary.
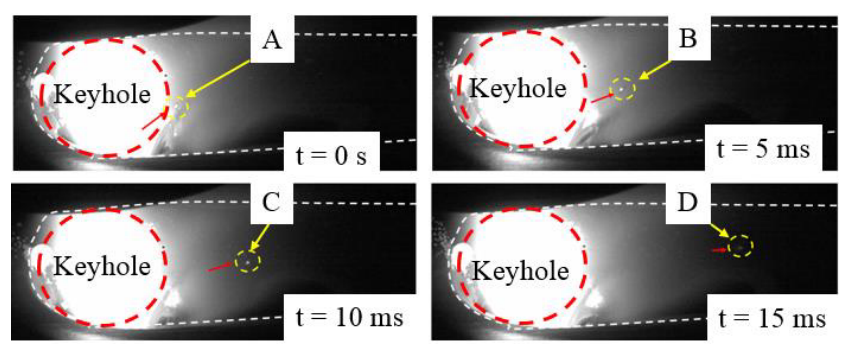

\section{Conclusions}

Several main results were drawn follows:

- The convective pattern on the top surface in both cases (pure Ar and $\mathrm{Ar}$ mixture with $10 \%$ hydrogen) was in circulated motions behind keyhole.

- The convective pattern on the bottom surface was transported to the rear part of weld pool in case of pure Ar.

- The convective pattern on the bottom surface was transported to center area of weld pool just behind keyhole in case of Ar mixture with $10 \%$ hydrogen.

- The velocity of convective pattern near the center line of weld pool was high, and it gradually decreased from center line to both sides of weld pool.

- The weld bead shapes were wide in case of Ar mixture with $10 \%$ hydrogen.

\section{Reference}

1) Nguyen Van Anh, Shinichi Tashiro, Bui Van Hanh and Manabu Tanaka: Visualization of weld pool convective flow in plasma keyhole arc welding, Frontier of applied plasma technology, 9 (2016), pp. 1-6.

2) M. Tanaka and J J Lowke: Predictions of weld pool profiles using plasma physics, J. Phys. D: Appl. Phys., 40 (2007), pp. 1-23.

3) W Lu, Y M, Zhang and John Emmerson: Sensing of weld pool surface using non-transferred plasma charge sensor, Meas. Sci. Technol., 15 (2004), pp. 991-999.

4) Zhang Y M, Zhang S B and Liu Y C: Plasma cloud charge sensor for pulse keyhole process control, Trans. Sci. Technol., 12 (2001), pp. 1365-1370.

5) Z. M. Liu, C. S. Wu and J. Chen: Sensing dynamic keyhole behaviors in controlled-pulse keyholing plasma arc welding, Welding journal, 92 (2013), pp. 381-389.

6) Satoshi Yamane, Hikaru Suzuki, Jiro Toma, Takahiro Godo, Kazumichi Hosoya, Tooru Nakajima and Hikaru Yamamoto: Imaging processing of the weld pool in robot plasma welding system, Quarterly Journal of the Japan welding society, 31 (2013), pp. 44-47.

7) S. Yamane, T. Godo, K. Hosoya, T. Nakajima and H. Yamamoto: Detecting and tracking of welding line in visual plasma robotic welding, Quarterly Journal of the Japan welding society (in Japanese), 31 (2013), pp. 175-180.

8) Yamane Satoshi: Tracking of welding using image processing, Quarterly Journal of the Japan welding society (in Japanese), 84 (2015), pp. 35-42.

9) Z. M. Liu, C. S. Wu and J. Chen: Sensing dynamic keyhole behaviors in controlled-pulse keyholing plasma arc welding, Welding journal, 92 (2013), pp. 381-389.

10) Matsuda Shoichi, Takahara Yasushi: Flows and temperature distribution of molten pool in Electromagnetic controlled molten pool welding process, Quarterly Journal of the Japan welding society (proceeding), 97 (2015), pp. 378-379.

11) R. Zong, J. Chen, C. S. Wu \& G. K. Padhy: Influence of molten metal flow on undercutting formation in GMAW, Journal of material processing technology, 234 (2016), pp. 169-176.

Fig. 7 Time sequential figures on upward flow on weld pool surface. 